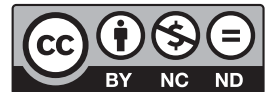

Estudos Teológicos foi licenciado com uma Licença Creative Commons Atribuição - NãoComercial - SemDerivados 3.0 Não Adaptada

http://dx.doi.org/10.22351/et.v60i1.3912

\title{
A CONTRibuição do Pentecostalismo na PROMOÇão DOS DIREITOS HUMANOS DOS NEGROS ${ }^{1}$
}

\author{
The contribution of Pentecostalism to the promotion \\ of black people's human rights
}

\section{Adriano Sousa Lima ${ }^{2}$ Luiz Alexandre Solano Rossi ${ }^{3}$}

\begin{abstract}
Resumo: O Brasil foi o último país do mundo a abolir o regime escravocrata. A escravidão foi intensa nas terras brasileiras, a ponto de criar costumes, normas e profundas desigualdades. Nos Estados Unidos, especificamente em Los Angeles, no século XIX e início do século XX, não ter relações com pessoas negras significava boa reputação e dignidade. Igualmente intensa foi (e ainda é) a luta em defesa dos direitos humanos dos negros. Nesse contexto, a Missão da Fé Apostólica, na rua Azusa, em Los Angeles, entre os anos 1906 a 1909 é referência fundamental. Naquela comunidade, homens e mulheres, brancos e negros participavam juntos das reuniões litúrgicas e conviviam em comunhão uns com os outros. O combate ao racismo naquela comunidade pentecostal era uma doutrina ensinada por William Seymour, o bispo da igreja, considerado o fundador do pentecostalismo. $\mathrm{O}$ presente texto tem como objetivo apresentar a contribuição do pentecostalismo da Missão da Fé Apostólica na promoção dos direitos humanos dos negros. Para os autores, a comunidade pentecostal sob a liderança de William Seymour é exemplo a ser seguido pelas igrejas cristãs brasileiras no que se refere ao combate a toda discriminação em virtude da cor da pele, contribuindo para a construção de uma sociedade livre e justa, com igualdade e solidariedade.
\end{abstract}

Palavras-chave: Direitos Humanos. Pentecostalismo. Racismo. Dignidade humana.

Abstract: Brazil was the last country in the world to abolish slavery. It was intense in Brazilian territories, creating habits, norms and profound inequalities. In the United States, specifically in Los Angeles, in the 19th century and in the beginning of the 20th, not having relationships with black people meant good reputation and dignity. Equally intense was (and still is) the struggle in defense of black people's human rights. In this context the Apostolic Faith Mission at Azusa Street, between 1906 and 1909, is

1 O artigo foi recebido em 24 de fevereiro de 2020 e aprovado em 13 de abril de 2020 com base nas avaliações dos pareceristas ad hoc.

2 Doutor em Teologia. FABAPAR/UNINTER. E-mail: adriano.lima.66@hotmail.com

3 Doutor em Ciências da Religião. PUCPR/UNINTER. E-mail: luizalexandrerossi@yahoo.com.br 
the main reference. In that community, men and women, white and black people used to attend services and to live in mutual communion. The fight against racism in that Pentecostal community was a doctrine taught by William Seymour, bishop of that church, considered the founder of Pentecostalism. The present text aims to present the Apostolic Faith Mission contribution to the promotion of black people's human rights. The author considers that the Pentecostal community under the leadership of William Seymour is an example to be followed by Brazilian Christian churches regarding color prejudice, contributing to the construction of free and fair society with equality and solidarity.

Keywords: Human rights. Pentecostalism. Racism. Human dignity.

\section{Introdução}

Os direitos humanos estão na base das principais discussões da atualidade. Certamente, nunca vivemos um período na história em que se falou tanto em direitos humanos. Afinal, o que são os direitos humanos? Quais seus fundamentos? É necessário a teologia pentecostal estabelecer um diálogo com os direitos humanos? $\mathrm{O}$ presente texto faz uma reflexão sobre o tema, considerando o desafio da prevalência dos direitos humanos presente na contemporaneidade.

Após a Segunda Guerra Mundial, diante da fragilidade da vida humana, diversos setores da sociedade passaram a refletir sobre a necessidade da valorização e do cuidado da vida. Nesse contexto, a dignidade humana tornou-se um dos elementos mais importantes e paradigmáticos na interpretação da realidade. Diante dos horrores das duas guerras, agora, seria necessário refletir sobre caminhos para proteção e promoção da vida humana, na sua integralidade. Os regimes totalitaristas precisavam ser freados, sob o risco de total destruição da humanidade. Em diversos países do mundo, a situação da vida humana era dramática. Nesse contexto de violência, o racismo atingia (e ainda atinge) muitas sociedades ditas civilizadas. No Brasil, não era (e não é) diferente.

O Brasil vive ainda na contemporaneidade situações diversas de violência motivada pela cor da pele, pela raça e etnias. Divergências salariais entre brancos e negros, o maior percentual da população universitária é branca ao mesmo tempo em que nas cadeias do Brasil o maior percentual é de negros. A situação é ainda pior quando a referência são as mulheres. As desigualdades entre mulheres brancas e negras são alarmantes. Em pleno século XXI, os negros experimentam na pele (e por causa da pele) as profundas angústias provocadas pela discriminação racial. Lamentavelmente, a cor da pele define muita coisa no Brasil.

No início do século XX, nos Estados Unidos da América, mais especificamente na rua Azusa 312, em Los Angeles, iniciara um movimento religioso que se tornaria a maior tradição evangélica do Brasil. O pentecostalismo teve início sob a liderança influente de William Seymour, filho de ex-escravos, negro e militante na defesa dos direitos humanos dos negros. O presente texto reflete sobre a contribuição do pentecostalismo da rua Azusa no combate ao racismo e na promoção dos direitos humanos dos negros. Na primeira parte do texto, faz-se uma análise do conceito e do fundamento dos direitos humanos. Na segunda parte, enfrentaremos uma página triste 
da história brasileira, a saber, o racismo no Brasil. Na penúltima parte, nossa atenção continua no racismo, mas desta vez sob a perspectiva dos direitos humanos. Finalmente, apresentaremos na última parte a contribuição do pentecostalismo no combate ao racismo, com o foco nos anos iniciais, especificamente em Azusa, sob a liderança de William Seymour, e algumas implicações práticas para a pastoral cristã.

\title{
Direitos humanos: conceito e fundamento
}

Inicialmente, convém apresentar o conceito de direitos humanos. Assumimos a definição tal como nos apresentam os teóricos do direito. A jurista e professora Maria Helena Diniz apresenta a seguinte definição para direitos humanos:

\begin{abstract}
Conjunto de normas substantivas contidas na Declaração Universal dos Direitos do Homem e não nas normas constitucionais, arrolando os direitos elementares à dignidade humana, sejam eles civis, políticos, econômicos, sociais ou culturais, aplicáveis aos homens individualmente ou como membros da sociedade [...] conjunto de normas e instituições voltadas ao resguardo da dignidade, liberdade e igualdade humana, que constituem o fundamento do Estado democrático ${ }^{4}$.
\end{abstract}

Diniz compreende que os direitos humanos nascem sistematicamente com a Declaração Universal dos Direitos do Homem. E constitui importante destacar, como deixa claro a definição, que quando falamos dos direitos humanos, estamos falando de normas e instituições voltadas ao resguardo da dignidade, liberdade e igualdade humana. O professor de Direitos Humanos da USP - Largo São Francisco, André de Carvalho Ramos, afirma que "os direitos humanos consistem em um conjunto de direitos considerado indispensável para uma vida humana pautada na liberdade, igualdade e dignidade. Os direitos humanos são os direitos essenciais e indispensáveis para uma vida digna". Liberdade, igualdade e dignidade são valores fundamentais da vida humana e, portanto, legítimos e dignos da nossa luta e do nosso comprometimento.

Os três princípios fundamentais (liberdade, igualdade e dignidade) que estão na base dos direitos humanos são também seus fundamentos. Mas, especificamente, vamos destacar a dignidade humana. Kant, na Fundamentação da Metafísica dos Costumes, afirma: "No reino dos fins tudo tem um preço ou uma dignidade. Quando uma coisa tem um preço, pode-se pôr em vez dela qualquer outra como equivalente; mas quando uma coisa está acima de todo o preço e, portanto, não permite equivalente, então ela tem dignidade". A luta incansável pelos direitos humanos tem como fundamento principal a dignidade da pessoa humana. Logo, lutar pelos direitos humanos é lutar pela dignidade da vida humana. A Declaração Universal dos Direitos Humanos é incisiva:

$\begin{array}{ll}4 & \text { DINIZ, Maria Helena. Dicionário juridico universitário. São Paulo: Saraiva, 2017. p. } 224 . \\ 5 & \text { RAMOS, André de Carvalho. Curso de Direitos Humanos. São Paulo: Saraiva, 2018. p. } 29 . \\ 6 & \text { KANT, Immanuel. Fundamentação da Metafísica dos Costumes. Portugal: Edições 70, 2011. p. } 82 .\end{array}$ 
Considerando que o reconhecimento da dignidade inerente a todos os membros da família humana e dos seus direitos iguais e inalienáveis constitui o fundamento da liberdade, da justiça e da paz no mundo. Todos os seres humanos nascem livres e iguais em dignidade e em direitos. Dotados de razão e de consciência, devem agir uns para com os outros em espírito de fraternidade.

Portanto fica claro que os direitos humanos têm um conceito arraigado na dignidade humana, que é também seu fundamento principal. Vale ainda destacar que o princípio da dignidade humana é norteador, constitutivo e base importante no direito constitucional, jamais ocupando um lugar periférico ou irrelevante. Portanto é importante mencionar o artigo $1^{\circ}$ da Constituição da República e destacar o terceiro fundamento:

A República Federativa do Brasil, formada pela união indissolúvel dos Estados e Municípios e do Distrito Federal, constitui-se em Estado Democrático de Direito e tem como fundamentos:

I - a soberania;

II - a cidadania;

III - a dignidade da pessoa humana;

IV - os valores sociais do trabalho e da livre iniciativa;

V-o pluralismo político ${ }^{7}$.

O princípio da dignidade humana constitui um dos fundamentos do Estado Democrático de Direito. O constituinte original reconhece a importância da proteção e da promoção da dignidade da pessoa humana como elementos fundamentais para o fortalecimento da democracia. Tal fundamento não aparece apenas na Constituição brasileira, mas em diversas cartas constitucionais estrangeiras. Apenas para mencionar alguns exemplos: Constituição da Alemanha (Art. $1^{\circ}$, inc. 1), Espanha (preâmbulo e Art. $10^{\circ} .1$ ), Grécia (Art. $2^{\circ}$, inc. 1) e Portugal (Art. $1^{\circ}$ ). No âmbito latino-americano, além da já mencionada Carta Magna brasileira (Art. $1^{\circ}$ inc. III), é possível mencionar as Constituições de países como Paraguai (preâmbulo), Cuba (Art. $9^{\circ}$ ), Chile (Art. $1^{\circ}$ ), Guatemala (Art. $4^{\circ}$ ), Peru (Art. $1^{\circ}$ e $3^{\circ}$ ) e Bolívia (Art. $6^{\circ}$ inc. II). A presença consolidada do princípio da dignidade humana em diversas cartas constitucionais demonstra quão sólida e importante é a compreensão de que o ser humano não pode ser tratado como meio, mas como fim em si mesmo. É fundamental compreender, como destaca Ingo Sarlet, o caráter jurídico-normativo da dignidade da pessoa humana e, portanto, do reconhecimento de sua plena eficácia na ordem constitucional, onde aparece como valor fundamental do Estado Democrático de Direito. ${ }^{8}$

7 BRASIL. Constituição da República Federativa do Brasil. São Paulo: Saraiva, 2017.

8 SARLET, Ingo. Dignidade humana e direitos fundamentais na Constituição Federal de 1988. 10. ed. São Paulo: Livraria do Advogado, 2015. p. 84. 


\section{Racismo no Brasil}

O Brasil foi o último país do mundo a abolir o regime escravocrata. As professoras Lilia Schwarcz e Heloisa Starling citam a definição de escravos do jesuíta Antonil para quem os escravos eram como as mãos e os pés do senhor do engenho, porque sem eles no Brasil não era possível fazer, conservar e aumentar fazenda, nem ter engenho corrente. As professoras lembram ainda que os escravos eram o real alicerce da sociedade e no recôncavo baiano chegaram a constituir mais de $75 \%$ da população. ${ }^{9}$ A escravidão foi intensa na terra de Santa Cruz, a ponto de criar costumes, normas, desigualdades etc. De todo modo:

A escravidão se enraizou de tal forma no Brasil, que costumes e palavras ficaram por ela marcados. Se a casa-grande delimitava a fronteira entre a área social e a de serviços, a mesma arquitetura simbólica permaneceria presente nas casas e edifícios, onde, até os dias que correm, elevador de serviço não é só para carga, mas também e, sobretudo, para os empregados que guardam o passado africano na cor [...] Era difícil escapar da escravidão. Aliás, no caso brasileiro ela tomou o território todo, e foi responsável pela maior importação forçada de trabalhadores africanos até hoje conhecida. E, de tão disseminada, a instituição deixou de ser privilégio de grandes senhores de engenho. Padres, militares, funcionários públicos, artesãos, taberneiros, comerciantes, pequenos lavradores, pobres e remediados, e até libertos possuíam escravos. Por essas e por outras é que a escravidão foi mais que um sistema econômico: ela moldou condutas, definiu desigualdades sociais, fez de raça e cor marcadores de diferenças fundamentais, ordenou etiquetas de mando e obediência, e criou uma sociedade condicionada pelo paternalismo e por uma hierarquia irrestrita. ${ }^{10}$

A maneira como as estudiosas descrevem a escravidão no Brasil demonstra com absoluta clareza que tal instituto foi abolido na teoria, mas permanece vivo em atitudes, serviços e condutas presentes na sociedade contemporânea. Ainda mais complexa e lamentável era o regime de trabalho dos escravos. O trabalho braçal que demandava muito esforço físico era relegado aos africanos, pois era considerado aviltante. Os trabalhadores tinham que enfrentar o calor insuportável das fornalhas, podendo sofrer queimaduras e ficar com o corpo todo marcado. Era uma atividade penosa e perigosa. Há registros de "cativos queimados na face e no peito, chamuscados com cera quente, torturados com ferro em brasa, que tiveram nariz e orelhas decepados"11. Lamentavelmente, verifica-se uma certa institucionalização de uma violência sem precedentes que deixou marcas (literalmente) no ser humano. A escravidão não foi apenas um período da história do país, mas uma realidade que ainda hoje faz parte da sociedade e da experiência de muitas pessoas. Embora muitas pessoas considerem que a escravidão seja uma página virada e alguns se autoproclamem inocentes, pois "nunca escravizaram ninguém", sabe-se que esse é um tema a ser enfrentado com coragem

\footnotetext{
9 SCHWARCZ, Lilia; STARLING, Heloisa. Brasil: uma biografia. São Paulo: Companhia das Letras, 2015. p. 79.

${ }^{10}$ SCHWARCZ; STARLING, 2015, p. 92, 96.

11 SCHWARCZ; STARLING, 2015, p. 93.
} 
e responsabilidade. A sociedade convive com a prática cotidiana do trabalho escravo (disfarçado de trabalho assalariado) e constantes discriminações raciais apresentadas nas suas diversas formas. Nesse contexto, é necessário conscientizar-se cada vez mais da atualidade, do desafio e da urgência dessa luta.

No Brasil, a luta contra o racismo é um grande desafio. A professora Maria de Lourdes Siqueira, maranhense, nascida em um quilombo no município de Codó, afirma que "infelizmente na vigência do sistema capitalista de produção, nós convivemos com um refinamento, uma reelaboração, reatualização dos princípios que nortearam o processo colonial escravista". E prossegue: "Há um requinte de colonialismo. Nossa sociedade ainda é colonial. O tratamento é desigual, há falta de respeito a direitos"12. Em tese semelhante, o professor Jessé Souza, em seu livro A Elite do Atraso, afirma que: "no Brasil, desde o ano zero, a instituição que engloba todas as outras é a escravidão. Nossa forma de família, de economia, de política e de justiça foi toda baseada na escravidão". O sociólogo afirma ainda que, embora exista um reconhecimento da escravidão, no sentido de que todos falam nela, nem todos compreendem o conceito. Existe uma diferença entre conceito e nome. É essa diferença que separa o senso comum da ciência. Com precisão cirúrgica, Souza destaca que "pode-se falar de escravidão e depois retirar da consciência todos os seus efeitos reais e fazer de conta que somos continuação de uma sociedade não escravista"'13. Quando, na verdade, a escravidão é exatamente o nosso problema. É nesse sentido que o professor Souza afirma que o problema do Brasil não é a corrupção, mas a escravidão alinhada com a negação de direitos. O problema é a negação de direitos. A sociedade brasileira convive com muita tranquilidade e naturalidade com as desigualdades. As desigualdades são naturalizadas por uma ideologia perversa que legitima a negação de direitos ao cidadão. Nesse contexto, as ações afirmativas compensatórias são necessárias, enquanto existir hierarquização das diferenças culturais e raciais.

O historiador Jaime Pinsky, que foi professor da UNESP, USP e UNICAMP acompanha a professora Maria de Lourdes Siqueira no entendimento de que a escravidão ainda está presente no tempo contemporâneo, sendo um dos grandes problemas da sociedade. Para Pinsky, houve um significativo avanço, contudo, a escravidão ainda está presente nas relações cotidianas. Essa presença da escravidão desdobra-se na prática constante da violência. Embora algumas pessoas insistam em negar o aspecto abusivo e repressor da violência no regime escravagista, sabe-se que escravidão e violência são inseparáveis. Pinsky faz questão de denunciar essa ladainha:

Ainda há autores que insistem em mostrar um país que privilegia o caráter cordial que sempre teria caracterizado as relações entre os brasileiros. Aqui tudo teria sido diferente - e mais pacífico. A independência ocorreu quando um membro da própria família real se deu conta de que ela era necessária: sem sangue. A abolição foi decretada pelas mimosas mãos de uma suave princesa: também sem sangue. A República foi proclamada durante um pacífico passeio de um militar e sua comitiva pelas ruas do Rio,

${ }_{12}$ FREITAS, Ana Tereza Silva de. Direitos humanos e diversidade. Curitiba: Joruá, 2013. p. 53.

${ }^{13}$ SOUZA, Jessé. A Elite do Atraso - da escravidão à lava jato. Rio de Janeiro: Leya, 2017. p. 14. 
outra vez sem sangue. E mesmo as rebeliões e quarteladas teriam ocorrido em nosso abençoado país sem violência alguma [...] Além de ser mentirosa (todos sabemos que a ditadura militar usou da tortura institucional como instrumento de repressão), essa visão da nossa História esquece deliberadamente a violência do dia a dia, a fome, a falta de condições de higiene e de moradia, a obrigação do trabalho sem lazer a que é submetida a maior parte da população. Vendendo a imagem do brasileiro pacífico, procura desautorizar eventuais manifestações dos oprimidos contra o atual estado de coisas, sob a alegação de que não seria uma atitude brasileira. Assim, a violência institucionalizada - a repressão - acaba sendo justificada em nome da luta contra a violência popular ${ }^{14}$.

A escravidão institucionalizada é, portanto, uma forma de violência talvez mais cruel do que aquela realizada nas senzalas. Agora não mais com chicotes pontiagudos, mas disfarçada de salários baixos, condições mínimas de trabalho e nas suas formas de desigualdade salarial entre brancos e negros. A discriminação, o preconceito e a desigualdade racial, lamentavelmente, constituem realidades presentes na sociedade brasileira, que devem ser enfrentadas com seriedade e responsabilidade. A situação é tão complexa no Brasil, que na vigência do governo do ex-presidente Lula foi necessário criar uma Secretaria Especial para tratar a promoção da existência da igualdade racial, entendendo assim de maneira formal que existem desigualdades. Depois de 500 anos, um Estado ser obrigado a criar uma secretaria para promover igualdade racial é um fato de extrema importância, que denuncia uma vergonha.

A sociedade brasileira é marcada pela diversidade étnica, que faz parte dos componentes de sua cultura. Historicamente, porém, não têm sido poucos os entraves encontrados pelos diversos contextos sociais para a efetivação desse reconhecimento. Indiscutivelmente, esses novos horizontes precisam se descortinar em nosso país a partir da ação contínua de uma teologia pentecostal, alinhando a produção acadêmica à vivência prática, transformando as pessoas em sujeitos de denúncias e de alertas para a urgência na construção de uma sociedade livre, justa e solidária, como preconizado pelo Constituinte. Contudo, antes de adentrar especificamente na contribuição pentecostal no combate ao racismo, será apresentado o racismo sob a perspectiva dos direitos humanos.

\section{Combate ao racismo sob a perspectiva dos direitos humanos}

Inicialmente, deve ser mencionado o segundo artigo da Declaração Universal dos Direitos Humanos: "Toda pessoa tem capacidade para gozar os direitos e as liberdades estabelecidas nesta Declaração, sem distinção de qualquer espécie, seja de raça, cor, sexo, língua, religião, opinião política ou de outra natureza, origem nacional ou social, riqueza, nascimento ou qualquer outra condição”. A Declaração de 1948 é fundamento básico e influente na luta contra o racismo. Já no ano de 1965, a Organização das Nações Unidas (ONU) adotou a Convenção Internacional sobre a Eliminação de todas as formas de Discriminação Racial. Essa convenção assinala desde seu preâmbulo que qualquer "doutrina de superioridade baseada em diferenças raciais é

14 PINSKY, Jayme. A escravidão no Brasil. São Paulo: Contexto, 2018. p. 72. 
cientificamente falsa, moralmente condenável, socialmente injusta e perigosa, inexistindo justificativa para a discriminação racial, em teoria ou prática, em lugar algum". $\mathrm{O}$ artigo $1^{\circ}$ da Convenção Internacional define discriminação racial como:

Toda distinção, exclusão, restrição ou preferência baseada em raça, cor, descendência ou origem nacional ou étnica que tenha por objeto ou resultado anular ou restringir o reconhecimento, gozo ou exercício em um mesmo plano (em igualdade de condição) de direitos humanos e liberdades fundamentais nos campos político, social, cultural ou em qualquer outro campo da vida pública.

A professora Flávia Piovesan destaca a proibição da discriminação em dois aspectos na Convenção: discriminação direta, que tem como propósito anular ou prejudicar o exercício de direitos humanos, e a discriminação indireta, que tem como efeito anular ou prejudicar o exercício desses direitos. Piovesan explica: "na discriminação direta há a intenção de discriminar; na discriminação indireta, uma suposta neutralidade vem de forma desproporcional a impactar grupos raciais, limitando o exercício de seus direitos"15. Sob essa perspectiva, é absolutamente necessário e urgente erradicar todas as formas de discriminação, baseadas em raça, cor ou origem étnica. Não apenas combater a discriminação, mas também promover políticas públicas de inclusão. Nesse aspecto:

Faz-se necessário combinar a proibição da discriminação com políticas compensatórias que acelerem a igualdade enquanto processo. Isto é, para assegurar a igualdade não basta apenas proibir a discriminação, mediante legislação repressiva. São essenciais estratégias promocionais capazes de estimular a inserção e a inclusão de grupos socialmente vulneráveis nos espaços sociais. Com efeito, a igualdade e a discriminação pairam sob o binômio inclusão-exclusão. Enquanto a igualdade pressupõe formas de inclusão social, a discriminação implica a violenta exclusão e intolerância à diferença e diversidade. Assim, a proibição da exclusão, em si mesma, não resulta automaticamente na inclusão. Logo, não é suficiente proibir a exclusão quando o que se pretende é garantir a igualdade de fato, com a efetiva inclusão social de grupos que sofreram e sofrem um consistente padrão de violência e discriminação. Desse modo, consagra a Convenção tanto a vertente repressivo-punitiva, pela qual é dever dos Estados proibir e eliminar a discriminação racial, como a vertente promocional, pela qual é dever dos Estados promover a igualdade ${ }^{16}$.

O desafio no combate ao racismo, tal como preconizado pela Convenção é amplo e diz respeito não apenas a eliminação do preconceito e da discriminação, mas também à promoção de políticas de inclusão. Nesse sentido, o papel dos Estados é fundamental, pois deve criar possibilidades, caminhos e políticas de exclusão do racismo e, ao mesmo tempo, promover a inclusão da igualdade racial. Diante de tal desafio, as diversas instituições presentes na esfera pública e privada, podem (e devem) contribuir. Aqui, especificamente, as religiões desempenham papel fundamental, no

15 PIOVESAN, Flávia. Direitos Humanos e Direito Constitucional Internacional. São Paulo: Saraiva, 2017. p. 288.

${ }^{16}$ PIOVESAN, 2017, p. 289. 
sentido de promover uma linguagem inclusiva e abrir espaço em suas liturgias para a promoção da igualdade racial e o combate ao racismo. Foi ninguém menos que Martin Luther King, pastor protestante norte-americano, que proclamou o discurso "Eu tenho um sonho", no 28 de agosto de 1963, comunicando seu sonho de harmonia racial e demonstrando absoluto compromisso na luta contra toda forma de discriminação racial existente nos Estados Unidos da América e no mundo. O pastor Luther King afirmou: "Eu tenho um sonho de que um dia esta nação se erguerá e viverá o verdadeiro significado da sua crença: consideramos estas verdades evidentes por si mesmas, que todos os homens são criados iguais"17. A partir dessa perspectiva, cada religião pode contribuir diretamente no combate ao racismo e promover a igualdade na sociedade. Certamente, uma religião descomprometida com essa perspectiva não pode ser uma religião legítima, muito menos oferecer algum sentido positivo para a vida humana.

\section{A contribuição do pentecostalismo no combate ao racismo}

A discriminação estrutural "consiste na sujeição de grupos historicamente vulneráveis a práticas constantes de negação de direitos ou tratamento discriminatório inferiorizante". No Brasil, o racismo institucional é constatado na manutenção das diferenças entre escolaridade, média salarial, acesso à saúde etc., entre brancos e afrodescendentes, o que implica o fracasso das políticas universalistas de implementação de direitos e promoção da igualdade, mais de 30 anos após a promulgação da Constituição Federal. Nesse sentido, a Lei n. 12.228/2010, que institui o Estatuto da Igualdade Racial, define a desigualdade racial como toda situação injustificada de diferenciação de acesso e fruição de bens, serviços e oportunidades, nas esferas pública e privada, em virtude de raça, cor, descendência ou origem nacional ou étnica.

Contemporaneamente sabe-se que o pentecostalismo não desfruta de uma relação amistosa com os direitos humanos. Contudo, deve-se dizer que, nos anos iniciais de sua história, o pentecostalismo demonstrou comprometimento com temas essenciais aos direitos humanos. Sim, nos anos iniciais, o pentecostalismo tinha um especial compromisso com os direitos humanos, especificamente com os direitos humanos dos negros, que precisa ser resgatado. Destaco o fundamento para a presente afirmação: 1) A rua Azuza, 312, na cidade de Los Angeles, no início do século XX, é considerada o marco do nascimento do pentecostalismo moderno, tendo como líder William Seymour, o "apóstolo negro", filho de ex-escravos. É importante aqui uma pequena descrição (com mais detalhes) sobre esse líder pentecostal:

Pastor da Apostolic Faith Mission (Missão da Fé Apostólica), Rua Azusa 312, Los Angeles (Califórnia), EUA, durante o avivamento da Rua Azusa, de 1906 a 1909. Considerado o pregador do Movimento Pentecostal nos Estados Unidos. William Seymour nasceu em 2 de maio de 1870, em Centerville, uma pequena cidade, cerca de $120 \mathrm{~km}$ a

17 KING, Martin Luther apud BURNET, Andrew. 50 discursos que marcaram o mundo moderno. Porto Alegre: L\&PM, 2018. p. 145. 
sudoeste de Nova Orleans. A região era conhecida por sua plantação de cana de açúcar [sic], o domínio católico romano e a presença de expressões religiosas sincréticas [...] Seymour era o filho mais velho de Simon e Phillis, seu pai, nascido por volta de 1841, foi oleiro, um negócio que frequentemente estava ligado à cana de açúcar [sic]. Sua mãe nasceu por volta de 1845. Ambos haviam sido escravos, e durante a Reconstrução, trabalharam duro para sustentar sua crescente família ${ }^{18}$.

Como se sabe, Seymour participava das aulas na Escola Bíblica Betel do lado de fora da sala para não se misturar com os alunos brancos de Parham. No ano de 1906, Seymour recebeu o convite do "povo negro da cidade de Los Angeles" para assumir o pastorado de uma pequena igreja de santidade. Vinte e cinco anos mais tarde, na comunidade negra de Los Angeles, Seymour seria lembrado como "um homem com uma missão de fundar uma igreja composta de crentes de todas as raças". A lembrança é justificável, pois, sob a liderança de Seymour, trabalhava uma equipe capaz e inter-racial, formada de mulheres e homens.

Nota-se ainda que nos anos iniciais da sua conversão, Seymour conheceu a Igreja Metodista Episcopal em Indianápolis. Era uma igreja inter-racial, comprometida com a inclusão de negros na comunidade. Alguns apontam que teria sido nessa igreja a experiência de conversão e posterior filiação do pastor da Azusa. Certamente não seria de se estranhar, já que Seymour tinha essa percepção inicial de inclusão inter-racial. A oposição ao racismo era notória na Missão da Fé Apostólica, na Azusa, 312, como narra o biógrafo de Seymour:

O avivamento na Rua Azusa, sob a liderança de Seymour, também se opôs ao racismo e segregação da época, com negros e brancos adorando juntos, sendo liderados por um pastor negro. Frank Bartleman, um participante branco dos cultos na Rua Azusa, expressou o espírito daquelas reuniões históricas, afirmando que a linha racial havia sido lavada no sangue de Jesus. Houve uma grande efusão do Espírito Santo, e Seymour foi o líder escolhido por Deus neste momento crucial em que os afro-americanos não eram considerados por suas competências. Todavia, Seymour dissiparia esses mitos racistas liderando um dos maiores reavivamentos da história da igreja americana ${ }^{19}$.

A oposição ao racismo no início do século XX é não apenas uma atitude ousada, mas inovadora e corajosa. O líder da Missão da Fé Apostólica, que desde tenra idade conviveu com a discriminação racial, foi firme na defesa dos direitos humanos dos negros. Essa defesa acontecia tanto no aspecto formal como material, ou seja, ao mesmo tempo em que Seymour defendia os direitos dos negros, ele permitia que negros e brancos estivessem juntos adorando a Deus. Negros exerciam função de liderança na comunidade, ensinavam e participavam ativamente das decisões da igreja.

Apesar da experiência que veio da própria casa, Seymour conheceu pessoas fundamentais que influenciaram decisivamente na sua postura em defesa do seu povo

18 ARAÚJO, Isael. Dicionário do Movimento Pentecostal. Rio de Janeiro: CPAD, 2014. p. 779.
19 SYNAN, Vinson; FOX JR, Charles. William Seymour - a Biografia. Natal (RN): Carisma, 2017. p. 27. 
e na luta contra o racismo. Na sua caminhada, Seymour conheceu a Escola Bíblica de Martin Wells Knapp, evangelista metodista, ligado ao Movimento Holiness, que incluía os negros nas reuniões. Em uma de suas pregações, comentando o texto de Gálatas 3.28, Knapp afirmou:

Barreiras de raça, cor e posição social não têm lugar na Igreja de Cristo [...] Os clubes sociais baseados em tom de pele, alegando ser igrejas, mas tirando pedras de críticas e ostracismo aos santos de Deus por causa de casta ou cor, estão entre as mais estupendas fraudes de Satanás que amaldiçoa a terra hoje. Os que respeitam e os que selecionam pessoas [...] Que contraste com o Corpo de Cristo $^{20}$.

A pregação do evangelista metodista tem muita semelhança com as preleções que eram realizadas na igreja de Azusa e com os textos publicados por Seymour no jornal Fé Apostólica. É latente a influência de Knapp na vida e no ministério do apóstolo negro da Missão da Fé Apostólica. O inclusivismo racial e a igualdade no Espírito tornaram-se temas cotidianos na comunidade de Azusa.

A influência na vida e no ministério de Seymour veio também do chamado ministério dos Santos da Luz Noturna, da cidade de Cincinnati. Os Santos da Luz Noturna era um ministério dedicado em levar o evangelho aos negros, fundado por Daniel Warner, que tinha como um dos seus lemas a comunhão cristã sem distinção de raças. Ao se aproximar desse ministério, Seymour teve contato com uma literatura que defendia a igualdade racial e a erradicação do preconceito em virtude da cor. Além da literatura, a convivência nas reuniões ajudou Seymour a perceber no ministério um compromisso com a igualdade racial. Vinson Synan apresenta um panorama das reuniões:

\begin{abstract}
Não era raro que os membros de ambos os grupos étnicos comparecessem às mesmas reuniões de avivamento nas tendas, o que atraía a ira dos moradores locais por transgredir tabus raciais como assentos mistos. Em alguns casos, os brancos serviam como ministros para encontros multirraciais; em outros casos, os ministros negros assumiram a liderança. $\mathrm{O}$ padrão de unidade racial nas primeiras décadas do movimento foi impulsionado por uma leitura literal de Gálatas 3.28 como status normativo da verdadeira igreja do Novo Testamento: Em Cristo não há judeu nem grego; nem escravo nem livre, nem homem nem mulher; pois todos são um em Cristo Jesus ${ }^{21}$.
\end{abstract}

Como é perceptível, o contexto em que Seymour viveu antes de assumir a liderança na Azusa foi fundamental na sua formação ministerial. Pregações, livros e artigos vetando o racismo na comunidade de fé, a ponto de afirmar explicitamente que o preconceito de toda sorte deve ficar fora da igreja, contribuíram definitivamente na vida daquele que se tornaria um dos líderes mais influentes do pentecostalismo. Assim, o movimento pentecostal liderado por Seymour só poderia ser um espaço de inclusão, acolhimento e promoção da igualdade racial. Os pentecostais têm na vida e no ministé-

\footnotetext{
20 SYNAN; FOX, 2017, p. 30.
}

${ }^{21}$ SYNAN; FOX, 2017, p. 33. 
rio de Seymour um excelente exemplo a seguir. Se assim o fizerem, estarão contribuindo para a construção de uma sociedade livre e justa, com igualdade e solidariedade.

A atuação de Seymour no combate ao racismo (e portanto na luta pelos direitos humanos dos negros) foi brilhante e digna de destaque. Em 1915, ele publicou um livro de 95 páginas com o título: As doutrinas e disciplinas da Missão da Fé Apostólica de Los Angeles. No livro, debate teologicamente contra o racismo. Seymour ainda deu conselhos práticos "sobre como lidar com o aumento de tendências racistas". Em vários lugares de sua obra, direciona sua dor "para o que ele considerava como atitudes e ações com inspirações racistas". Se, de um lado, Parham tinha notórias inclinações racistas e simpatias com a Ku Klux Klan (talvez isso explique a opção política da maioria dos pentecostais brasileiros), do outro lado, Seymour, uma das principais referências do pentecostalismo mundial, deixou como legado a mensagem de reconciliação entre as raças e um sólido compromisso com o combate ao racismo.

\section{Implicações práticas para a pastoral cristã}

A partir do posicionamento de William Seymour, como um líder carismático, comprometido com os direitos humanos dos negros e militante na luta contra o racismo, é possível extrair algumas implicações práticas para a pastoral cristã. A Missão da Fé Apostólica, sob a liderança de Seymour, ficou mundialmente conhecida e recebeu visitantes do mundo inteiro, que vinham presenciar e vivenciar experiências espirituais. Contudo, lembra Vinson Synan, embora muitos testemunhos tenham sido registrados sobre os milagres que ocorreram em Azusa sob a liderança de Seymour, o maior milagre pode ter sido a harmonia inter-racial. Synan enfatiza:

Muitos historiadores são fascinados com a realidade de que pessoas de várias nacionalidades e raças compareceram aos cultos e se uniram sob um pastor negro da Lousiana. $\mathrm{O}$ fato de que negros e brancos trabalharam juntos na liderança do movimento durante o tempo em que as injustas leis de Jim Crow eram o precedente é ainda mais fascinante. O tipo de diversidade racial que esse avivamento desencadeou durante um determinado período foi notável. Mãos negras foram impostas sobre cabeças brancas, à medida que muitos receberam o batismo do Espírito $\mathrm{Santo}^{22}$.

A realidade eclesial da Missão da Fé Apostólica era realmente admirável e de certa forma um milagre. Um exemplo a ser seguido pelas igrejas brasileiras. Não se trata de uma igreja pentecostal do início do século XXI, mas de uma comunidade pentecostal em Los Angeles, Estados Unidos, no início do século XX. Num contexto onde o racismo era considerado como algo normal e havia igrejas exclusivas para brancos, na comunidade inclusiva liderada por Seymour, negros e brancos trabalhavam juntos, adoravam a Deus juntos e viviam em comunhão uns com os outros. $\mathrm{O}$ ensinamento contrário à escravidão não estava apenas nas pregações de Seymour, mas também no Manual de

22 SYNAN; FOX, 2017, p. 83. 
Doutrinas e Disciplinas, uma espécie de catecismo da Missão da Fé Apostólica. Dentre diversas orientações sobre matrimônio, como se portar no culto, orientações sobre a celebração da Ceia, do batismo e doutrinas fundamentais dos pentecostais da Missão, Seymour dedica um pequeno (mas precioso) parágrafo sobre escravidão. Diz ele:

\begin{abstract}
Nós declaramos que estamos convencidos do grande mal da Escravidão. Acreditamos que a compra, venda ou detenção de seres humanos, para ser usado [sic] como propriedades, é contrária [sic] às leis de Deus e à natureza, e é incoerente com a Regra de Ouro, e com a Regra de nossa Disciplina, que exige que todos os que desejam seguir entre nós não fazem o que é mal e evitam o mal de todo tipo. Por isso, admoestamos afetuosamente todos os nossos ministros e pessoas a manterem-se puros desse grande mal e buscar a sua extirpação por todos os meios legais e cristãos ${ }^{23}$.
\end{abstract}

Se, naquela época (final do século XIX e início do XX), andar com alguém de cor era algo que denegria a reputação de um americano branco de Los Angeles, na Missão da Fé Apostólica, os brancos não estavam preocupados com sua própria reputação. Para eles, a única coisa que importava era que eles tinham que receber a mensagem de Deus que William Seymour, o pastor negro, tinha para lhes transmitir. Que exemplo relevante e significativo para todos os cristãos e em especial para os pentecostais, pois a Missão da Fé Apostólica, na rua Azusa, é simplesmente um lugar constitutivo da fé pentecostal. Se os pentecostalismos brasileiros abandonaram Azusa, necessário e urgente é voltar às fontes e resgatar os ensinamentos e doutrinas daquela comunidade que colocou a defesa dos direitos humanos dos negros como um de suas bases doutrinárias.

\title{
Conclusão
}

Os direitos humanos, consagrados na Declaração Universal de 1948, são direitos e garantias fundamentais e essenciais para garantir a dignidade humana de cada pessoa. A partir da valorização e do respeito à vida digna, é possível construir uma sociedade onde homens e mulheres sejam vistos a partir da essência e não da cor da pele. Os direitos humanos fundamentais são caminhos para o combate intransigente das desigualdades, dos preconceitos e das discriminações, que provocam tanto sofrimento e produz muitas vítimas no mundo.

Assim, o compromisso no combate ao racismo é tarefa necessária, urgente e inadiável. Fundamentados na Constituição Federal, na Declaração Universal dos Direitos Humanos, nos diversos instrumentos internacionais e a partir da perspectiva interna da fé pentecostal, estimulados pelo exemplo de William Seymour e a Missão da Fé Apostólica, devemos lutar contra todas as formas de discriminação racial, numa postura profética, denunciando o racismo institucionalizado e muitas vezes disfarçado com uma nova roupagem.

${ }^{23}$ SEYMOUR apud SYNAN; FOX, 2017, p. 304. 
A comunidade sob a liderança de William Seymour deixou um valioso e relevante exemplo para as igrejas cristãs, e mais especificamente para as igrejas pentecostais. Num país onde a violência contra os negros é alarmante, urge um compromisso de todas as tradições cristãs no sentido de defender a dignidade humana dos negros, combatendo o racismo e promovendo a igualdade racial. É tarefa da comunidade cristã defender a vida plena, abundante e digna. Nessa luta, todos somos convidados a participar de forma comprometida.

A sociedade contemporânea vive na era dos direitos, para usar a expressão do renomado jurista italiano Norberto Bobbio. Nesse contexto, o pentecostalismo é desafiado a lutar pelos direitos universais de cada ser humano. Podemos (e devemos) contribuir para a promoção da vida abundante no mundo. Assim, o chamado do discípulo de Jesus passa necessariamente pela luta e a defesa intransigente dos direitos humanos e da dignidade humana. E ainda: todas as pessoas cristãs devem lutar contra toda forma de escravidão e de racismo vigente na nossa sociedade. É necessário que o pentecostalismo (e as diversas tradições cristãs) reconheça os valores que a comunidade negra pode aportar e contribuir para que a sociedade seja melhor, seja mais humana, mais justa e mais igualitária.

\section{Referências}

ARAÚJO, Isael. Dicionário do Movimento Pentecostal. Rio de Janeiro: CPAD, 2014. BRASIL. Constituição da República Federativa do Brasil. São Paulo: Saraiva, 2017.

BAPTISTA, Douglas. Valores cristãos: enfrentando as questões morais do tempo. Rio de Janeiro: CPAD, 2018.

BURNET, Andrew. 50 discursos que marcaram o mundo moderno. Porto Alegre: L\&PM, 2018. DINIZ, Maria Helena. Dicionário jurídico universitário. São Paulo: Saraiva, 2017.

FREITAS, Ana Teresa Silva de. Direitos Humanos e Diversidades. Curitiba: Juruá, 2013.

KANT, Immanuel. Fundamentação da Metafísica dos Costumes. Portugal: Edições 70, 2011. PINSKY, Jayme. A escravidão no Brasil. São Paulo: Contexto, 2018.

PIOVESAN, Flávia. Direitos Humanos e Direito Constitucional Internacional. São Paulo: Saraiva, 2017.

RAMOS, André de Carvalho. Curso de Direitos Humanos. São Paulo: Saraiva, 2018.

SARLET, Ingo. Dignidade humana e direitos fundamentais na Constituição Federal de 1988. 10. ed. São Paulo: Livraria do Advogado, 2015.

SCHWARCZ, Lilia; STARLING, Heloisa. Brasil: uma biografia. São Paulo: Companhia das Letras, 2015.

SOUZA, Jessé. A Elite do Atraso - da escravidão à lava-jato. Rio de Janeiro: Leya, 2017.

SYNAN, Vinson; FOX JR, Charles. William Seymour - a Biografia. Natal (RN): Carisma, 2017. 